\title{
ASSESSING THE IMPORTANCE OF PROPERTY DEVELOPMENT RISK FACTORS
}

\author{
GRAEME NEWELL and MARK STEGLICK \\ University of Western Sydney
}

\section{ABSTRACT}

Property development makes a significant contribution to the Australian property industry and economy. However, property development is inherently risky, with a number of risks evident throughout the property development process. From a survey of leading property developers in Australia, the importance of 34 property development risk factors is assessed. The most important property development risk factors identified were environmental risk, time delay risk and land cost risk.

Keywords: Property development, risk factors, property development stages, environmental risk, time delay risk, land cost risk

\section{INTRODUCTION}

The property development industry includes a wide range of organisations and individuals involved in developing and operating property to meet the housing, employment and social needs of communities (UDIA, 2003). Importantly, property development makes a significant contribution to the Australian property industry and economy, with Table 1 profiling the contributions of the NSW and Queensland property development sectors ${ }^{1}$ (Ernst \& Young, 2002, 2003).

In 2001-02, the NSW property development sector had a total annual turnover of $\$ 36.1$ billion, directly generating $\$ 16.6$ billion in added value and employing over 181,000 staff. The property development sector contributes $7 \%$ to the NSW economy (gross state product), being the $5^{\text {th }}$ largest sector contribution, only exceeded by manufacturing (12\%), ownership of dwellings (11\%), property and business services (10\%), and finance and insurance $(9 \%)$. Similarly, the property development sector contributes $6 \%$ to NSW employment, being the $6^{\text {th }}$ largest sector employer. When the flow-on effect into other sectors of the NSW economy is factored in, the total added value contribution to the NSW economy by the property development sector is $\$ 33.0$ billion and employment for over 444,000 (Ernst \& Young, 2003).

${ }^{1}$ Reports are only prepared for NSW and Queensland sectors 


\section{NSW profile}

- Total property development sector turnover : $\$ 36.1$ billion

- Contribution by NSW to Australian property development sector turnover : $34 \%$

- Direct added value to NSW economy (GSP) : \$16.6 billion

- Contribution to NSW economy (GSP) : 7\% (5 $5^{\text {th }}$ largest sector contribution)

- Directly employs over 181,000 (full-time equivalents); over $\$ 5.9$ billion in wages

- Contribution to NSW employment : $6 \%\left(6^{\text {th }}\right.$ largest sector contribution $)$

- Flow-on contribution : $\$ 16.4$ billion in added value and 262,000 jobs

- Total NSW property development sector contribution : $\$ 33.0$ billion in added value, employing 444,000

\section{Queensland profile}

- Total property development sector turnover : $\$ 25.5 \mathrm{~B}$

- Contribution by Queensland to Australian property development sector turnover : $19 \%$

- Direct added value to Queensland economy (GSP) : \$7.8 billion

- Contribution to Queensland economy (GSP) : 7\% (4 $4^{\text {th }}$ largest sector contribution)

- Directly employs over 116,000 (full-time equivalents)

- Contribution to Queensland employment : 8\% (5th largest sector contribution)

- Total Queensland property development sector contribution : $\$ 18.6$ billion in added value, employing 220,000

\section{Australian profile}

- Total property development sector turnover : $\$ 106$ billion

Source: Extracted from Ernst \& Young $(2002,2003)$ 
Similar significant contributions (see Table 1) are also seen from the property development sector in Queensland (Ernst \& Young, 2002). With NSW contributing approximately $34 \%$ to Australian turnover, the annual turnover of the Australian property development sector is over $\$ 106$ billion (Ernst \& Young, 2003).

Table 2 presents the performance analysis at December 2004 for the listed property development sector compared to the other major asset classes (UBS, 2005). The property development sector is clearly more volatile (annual risk $=15.6 \%$ ) than the LPT sector $(7.2 \%)$ and the stockmarket $(9.1 \%)$. Strong risk-adjusted performance is seen from a number of property developers (eg: Sunland, Village World and FKP), but high levels of volatility are also evident in this individual property developer performance. The potential significant risk-adjusted performance contribution by property development to LPTs via the stapled securities structure has also been identified (Tan, 2004).

Overall, property development is inherently risky, with high barriers to entry reflecting the cyclic and capital intensive nature of the sector, and the typically slow payback period. This sees a number of risks evident throughout the property development process and the need for effective risk management strategies for successful property developments. Given the significance of the property development sector in Australia and internationally, it is important to identify the various property development risks and the importance of these risk factors in the property development process. As such, this paper presents the results of a survey of leading property developers in Australia to assess the importance of specific property development risk factors in the property development process.

\section{PROPERTY DEVELOPMENT RISK}

All aspects of property investment risk have received extensive coverage for many years; this includes the risk-reduction effects of property in a portfolio, portfolio risk reduction via property diversification, risk premiums for property sectors and the impact of valuation-smoothing on property risk (Booth et al, 2002). However, it has been recognised for many years that research into property development risk is limited (Whipple, 1988); particularly given the role of the property cycle and its strategic implications for property and property development (Pyhrr et al, 1999). 
Table 2 : Property developer and related sector performance : Dec. $2004^{1}$

\begin{tabular}{|c|c|c|c|c|c|c|}
\hline \multirow[t]{2}{*}{ Sector } & \multirow{2}{*}{$\begin{array}{c}\text { Market } \\
\text { cap (\$B) }\end{array}$} & \multicolumn{3}{|c|}{ Average annual total return } & \multirow{2}{*}{$\begin{array}{l}\text { Annual }^{2} \\
\text { risk }\end{array}$} & \multirow{2}{*}{$\begin{array}{r}\text { Sharpe }^{2,3} \\
\text { index }\end{array}$} \\
\hline & & $1 Y^{\circ}$ & $3 \mathbf{Y}$ & $5 Y$ & & \\
\hline $\begin{array}{l}\text { Property } \\
\text { development }\end{array}$ & $\$ 9.68 \mathrm{~B}$ & $42.2 \%$ & $7.9 \%$ & NA & $15.6 \%$ & $0.17(4)$ \\
\hline Lend Lease & $\$ 5.28 \mathrm{~B}$ & $37.5 \%$ & $3.5 \%$ & $-6.6 \%$ & $25.7 \%$ & -0.07 \\
\hline Australand & $\$ 1.53 \mathrm{~B}$ & $23.4 \%$ & $9.2 \%$ & $14.6 \%$ & $14.3 \%$ & 0.28 \\
\hline FKP & $\$ 0.68 \mathrm{~B}$ & $52.4 \%$ & $67.3 \%$ & $36.2 \%$ & $41.0 \%$ & 1.51 \\
\hline AV Jennings & $\$ 0.33 \mathrm{~B}$ & $-13.3 \%$ & $30.4 \%$ & $41.3 \%$ & $32.5 \%$ & 0.77 \\
\hline Sunland & $\$ 0.40 \mathrm{~B}$ & $74.9 \%$ & $70.9 \%$ & $34.7 \%$ & $34.5 \%$ & 1.90 \\
\hline Village Life & $\$ 0.33 \mathrm{~B}$ & $87.7 \%$ & NA & NA & NA & NA \\
\hline Village World & $\$ 0.17 \mathrm{~B}$ & $38.5 \%$ & $48.7 \%$ & $23.8 \%$ & $24.3 \%$ & 1.79 \\
\hline LPTs & $\$ 75.30 \mathrm{~B}$ & $32.2 \%$ & $17.2 \%$ & $16.9 \%$ & $7.2 \%$ & $1.65(1)$ \\
\hline Stockland & $\$ 7.73 \mathrm{~B}$ & $22.9 \%$ & $19.1 \%$ & $22.4 \%$ & $12.3 \%$ & 1.13 \\
\hline Mirvac & \$3.99B & $21.9 \%$ & $16.0 \%$ & $17.2 \%$ & $10.3 \%$ & 1.05 \\
\hline Multiplex & $\$ 3.24 \mathrm{~B}$ & $42.2 \%$ & NA & NA & NA & NA \\
\hline Shares & $\$ 847.89 \mathrm{~B}$ & $27.6 \%$ & $10.7 \%$ & $9.2 \%$ & $9.1 \%$ & $0.61(2)$ \\
\hline Bonds & NA & $6.7 \%$ & $5.9 \%$ & $6.8 \%$ & $3.0 \%$ & $0.21(3)$ \\
\hline Cash & NA & $5.6 \%$ & $5.1 \%$ & $5.4 \%$ & $0.1 \%$ & $-1.19(5)$ \\
\hline
\end{tabular}

1. Westfield is not included in performance analysis due to stapling of Westfield

Holdings, Westfield Trust and Westfield America Trust in 2004.

2. Risk measures based on 3-year monthly returns. Risk is calculated as the standard deviation of monthly returns over this three-year period.

3. Ranking based on risk-adjusted performance for major asset classes is given in brackets.

Source: Authors' compilation from UBS (2005)

Pacific Rim Property Research Journal, Vol 12, No 1 
With the chronological stages in the property development process being broadly identified (eg: Cadman and Topping, 1995; Miles et al, 2000), most approaches concentrate on measuring property development risk, rather than identifying or prioritising key risk elements in the property development process. These approaches largely concentrate on feasibility analysis and cashflow analysis (eg: Byrne, 1996; Cadman and Topping, 1995), with only limited attention given to property development risk management (eg: Cadman and Topping, 1995; Miles et al, 2000). A broad classification of property development risk into four categories (commercial, construction, land, social) and 21 sub-categories has also been developed (Dullisear, 2001). Other studies have largely concentrated on specific aspects of property development risk such as development financing risk (Markham, 2001) and interest rate risk (Cameron, 1990). Property development risk is only briefly addressed in the API's Professional Practice Standards via guidance note 6.2 (feasibility studies) and guidance note 6.6 (property development management) (API, 2004).

Overall, property development risk has received limited coverage. This area of property development risk management has taken on increased significance recently as leading property developers in Australia have recognised the need to further strengthen their risk management controls to maintain their discipline in bidding for work and to execute projects successfully. The following sections of this paper address this key issue in property development by assessing the importance of a range of property development risk factors based on a survey of the leading property developers in Australia.

\section{METHODOLOGY}

\section{Selection of property developers}

While the property development industry involves a large number of small, unlisted property developers accounting for 95\% of the sector's turnover (Ernst \& Young, 2003), the low level of publicly available data (eg: annual reports, financial statements) sees sufficient and reliable data on these unlisted property developers as not being available. As such, the listed property development sector was utilised for this study, representing the large property developers in Australia, as well as being a sector having high levels of disclosure and transparency.

The property developers selected were ASX-listed companies with their predominant activities being property development, rather than property investment or construction. The 24 listed property developers selected (see Table 3) had a total market capitalisation of $\$ 13.57$ billion at June 2003, representing 90\% coverage of the property development sector on the Australian stockmarket, as well as representing 5\% of the total Australian property development turnover. These property developers were further classified by size on the basis of annual turnover as: 
- $\quad$ large property developer ( $>\$ 100$ million): scale of operation includes multiple developments, predominantly multi-stage or national and multi-property sector; 10 selected

- medium property developer (\$20 million - \$100 million): scale of operation includes multiple developments, largely state-based and one property sector; 6 selected

- small property developer $(<\$ 20$ million): scale of operation includes single development or several small developments; 8 selected,

with Table 3 listing the various property developers selected. Residential property development was the major activity of most of these selected property developers, with residential development accounting for $71 \%$ of Australian property development gross output (Ernst \& Young, 2003).

\section{Survey construction}

After reviewing the available literature on property development risk (see previous section), 34 property development risk factors were identified throughout the chronological stages in the property development process; namely:

- pre-construction stage: 10 risk factors

- contract negotiation stage: 4 risk factors

- formal commitment stage: 3 risk factors

- construction stage: 8 risk factors

- post-construction (completion) stage: 9 risk factors.

Respondents were asked to rate each property development risk factor on a 5-point scale ranging from $1=$ low risk to $5=$ high risk. Respondents also identified specific risk management strategies employed by their company in mitigating each specific property development risk factor ${ }^{2}$.

\footnotetext{
${ }^{2}$ The survey section on the property development risk management strategies was addressed via open-ended questions. As such, it is not possible to identify the exact percentage of respondents who utilised a specific property development risk management strategy.
} 
Table 3 : List of property developers surveyed

Property developer

Large property developers : $>\$ 100 \mathrm{M}$ turnover

Australand

AV Jennings

Central Equity

Delfin

Devine

FKP

Mirvac

Sunland

Villa World

Westfield
Turnover

(\$M)

1158

466

221

NA

379

198

1027

206

216

967
Market cap. $^{2}$

(\$M)

839

353

144

NA

42

344

3038

110

129

8253

Medium property developers : \$20M-\$100M turnover

Canberra Investment $60 \quad 45$

Cedar Woods Properties

$26 \quad 48$

Finbar International

Kimberley Securities

Raptis Group

United Overseas Australia

Small property developers : $<\$ 20 M$ turnover

AHC

$5 \quad 9$

Axiom Properties

Balmoral

Folkestone

Port Bouvard

Metroland Australia

Payce Consolidated

1. Annual turnover for 2001-02

2. Market capitalisation at June 2003

3. Exceeds threshold turnover in year, but significantly below in previous years 
The mail surveys were distributed in May 2003 to the 24 property developers shown in Table 3. Surveys were sent to senior executives in each property development company who were familiar with all aspects of the property development process in their organisation. As all survey respondents were actively involved in residential property development, this was reflected in the residential property development sector being the focus for the respondents' risk factor assessments in this survey.

\section{SURVEY RESPONDENT PROFILE}

Of the 24 listed property developers initially selected, four declined to participate, giving an effective sample of 20 property developers. Eight property developers responded to the survey, giving a $40 \%$ response rate which was considered adequate. The respondents' annual turnover was in excess of $\$ 2$ billion, representing approximately $40 \%$ of the turnover for the listed property development companies in Australia. By scale of operations, respondents were large property developers (4), medium property developers (1) and small property developers (3).

All respondents indicated their organisation had formal processes for assessing property development risk before making a decision to proceed with a new development project. $100 \%$ of respondent's organisations also assessed individual property development risks before commencing a property development, as well as identifying specific risk management strategies for the property development.

$62.5 \%$ of respondents indicated that specific property development risk management strategies had been practiced by their organisation for more than ten years, with the remainder having these risk management strategies for an average of four years. No respondents outsourced any aspect of the property development risk assessment, although none used the Australian standard on general risk management (SA/SNZ, 1999).

A range of risk analysis techniques were used by the respondents, including:

- $\quad$ preparing a financial feasibility model : $100 \%$

- analysing the project using predetermined financial performance benchmarks : $100 \%$

- $\quad$ calculating IRR : $87.5 \%$

- preparing a sensitivity analysis : $87.5 \%$

- $\quad$ preparing a DCF model : 75\%

- $\quad$ preparing probability models : $37.5 \%$

- preparing risk simulations : $25 \%$,

further confirming the use of the standard techniques in property development risk analysis, as well as the more sophisticated property development risk analysis tools. 


\section{ASSESSING PROPERTY DEVELOPMENT RISK FACTORS}

The following sections assess the importance of the various property development risk factors across the five chronological phases in the property development process.

\section{Pre-construction risk}

Table 4 presents the pre-construction property development risk ratings. Given the uncertainty in the pre-construction phase and some factors being out of the developer's control, respondents considered this phase of the property development process to have the highest overall risk. Environmental risk (4.25) was seen as the highest risk factor in the pre-construction phase, as well as being the highest risk in the entire property development process. Approval risk (3.63) was seen as the fifth most important risk factor overall. In total, five of the top ten risk factors in the overall property development process were in the pre-construction phase.

Table 4 : Pre-construction property development risk ratings

Risk factor

Environmental : heritage, ecology, contamination

Approvals: zoning, compliance, conditions, developer contributions

Political : lack of support from local community, council, government

Experience with type of development, ability to manage development

Market : research, location, portfolio diversification

Title : land title problems and encumbrances

Consultants : design quality, reliability of consultant's report

Physical : difficult land form and existing improvements

Feasibility : assumptions, financial performance benchmarks, risk analysis

Infrastructure : availability of services, water, traffic, social infrastructure rating

4.25

Average risk 
The importance and high risk of the pre-construction phase is reflected in a large number of risk management strategies being employed in this phase, with 32 specific strategies identified as being employed by the respondents; these include:

- environmental risk: engaging expert consultants, analysing cost impacts before committing, making contracts conditional on resolving issues

- approvals risk: confirm pre-DA if extra approvals are needed, confirm basis of contributions, purchase conditional on rezoning, active liaison with Council

- political risk: work with community, be seen to have tried to address concerns, make legal contracts conditional for contentious developments

- experience risk: only deal with experienced developers and builders, investigate track record of successful developments, avoid one-off developments

- market risk: critically evaluate location, factor deficiencies into land price

- feasibility risk: disciplined approach, reject projects which are marginal and/or do not meet benchmarks.

\section{Contract negotiation risk}

The contract negotiation property development risk ratings are given in Table 5. This phase was seen by respondents as having the second highest overall risk, with land cost risk (3.88) and acquisition terms risk (3.75) being seen as the 3rd and 4th most important risk factors in the overall property development process. Specific strategies employed by the respondents include:

- land cost risk: negotiating price which provides for adequate contingencies

- acquisition terms risk: negotiate adjustment mechanisms for price and/or conditions

- building contract risk: negotiate fixed price contract, ensure architectural documentation is complete and buildable, use in-house estimating and construction management

- financial risk: use corporate funding facilities instead of property-specific funding facility. 
Table 5 : Contract negotiation property development risk ratings

Risk factor

Average risk rating

Land cost (allowing for reasonable profit margin)

3.88

Acquisition terms (fair, provide flexibility)

3.75

Building contract terms (allow control of costs)

Financial terms (not onerous)

\section{Formal commitment risk}

Table 6 presents the formal commitment property development risk ratings by the respondents. Whilst considered an important phase in the property development process, no specific risk factors in the formal commitment phase figured in the top ten risk factors overall. Risk management strategies (8) largely focused on adequate insurance being in place for both the developer and third parties, as well as not proceeding until all documentation has been executed.

\section{Table 6 : Formal commitment property development risk ratings}

Risk factor

Scope and adequacy of insurance coverage

All legal documentation executed

Binding pre-commitments to lease and/or purchase
Average risk rating

3.14

3.13

3.00

\section{Average formal commitment risk rating}

\section{Construction risk}

The construction property development risk ratings are shown in Table 7. Specific risk factors in this phase were seen by respondents to be highly important in the overall property development process; namely time delay risk (2nd), cost increase risk (5th) and engineering risk (7th). Of the thirteen risk management strategies utilised by the respondents, the main strategies were: 
- time delay risk: adequate insurance cover, penalty to builder

- cost increase risk: fixed price building contract

- solvency risk: step in rights to allow appointment of replacement

- project management risk: use in-house project manager

- experience risk: check past performance of builder regarding project completion on time and on budget

- environmental risk: establish site environmental management plan.

Table 7 : Construction property development risk ratings

\section{Risk factor}

Time delays ; weather, force majeure, strikes

Cost increases and unanticipated variations

Engineering problems (unexpected, poor design)

Solvency of builder

Quality of project management

Builder's experience in similar projects

Environmental (dust, noise, surface water etc. during construction)

Non-payment of sub-contractors
Average risk rating

4.14

2.86

2.75

2.75

2.00

Average construction risk rating

\section{Post-construction risk}

Table 8 presents the post-construction property development risk ratings by the respondents. The post-construction phase was seen as the least risky phase in the overall property development process, with only delivery timing risk (10th) being seen as a top priority risk factor. Risk management strategies in the post-construction phase (11) include revise prices to meet market, provide incentives, contingency marketing plan, pre-sale and pre-leasing strategy, and use of corporate branding. 
Table 8 : Post-construction property development risk ratings

Risk factor

Average risk

Timing of delivering development (cycle risk)

rating

Timing of delivering development (cycle risk)

3.38

Changes in market value and capitalisation rates

3.00

Unfavourable changes in demand and supply

2.88

Leases/sales pre-commitments fail to complete

Project commerce materially alters

Incorrect branding and image, market positioning image

Changes in interest rates, time cost of money

Financial : leverage, debt service, solvency, default, repayment

Political/economic : tax, inflation, regulations, laws

Average post-construction risk rating

Overall, Table 9 presents the top ten property development risk factors identified by respondents. Clearly pre-construction, contract negotiation and construction risk dominate this priority risk schedule. Of the 84 risk management strategies identified as being utilised throughout the property development process, the key strategies to mitigate property development risk were:

- in-house management of critical processes

- quality assurance procedures

- contractually allocating risk to other parties. 
Risk factor

Average risk

1st : Environmental risk

rating

1st: Environmental risk

2nd: Time delay risk

4.14

3rd : Land cost risk

4th : Acquisition terms risk

5th : Approvals risk

5th : Cost increases risk

7th : Political risk

7th : Experience risk

7th : Engineering risk

10th : Market risk

10th : Delivery timing risk

\section{Impact of scale of operation}

To assess the impact of the scale of operation of property development on these property development risk ratings, Table 10 presents the risk ratings for the five stages of the property development process for large, medium and small scale property developers. Whilst, overall, respondents perceive the average risk level decreases as the stages of the property development process advance, clear differences are seen between the different scales of operation of property development. The larger property developers placed a higher overall importance on the risk factors, with medium-sized property developers placing more importance on risk in the formal commitment, construction and postconstruction phases. This reflects their concerns in the implementation and delivery phases of the property development process and where their risk management strategies are potentially weakest. 
Table 10: Impact of scale of operation of property development on risk ratings

\begin{tabular}{lcccc}
\hline Stage of development & Total & Lverage risk ratings & \\
& 3.20 & 3.60 & 2.70 & 2.83 \\
Pre-construction & 3.19 & 3.50 & 3.75 & 2.58 \\
Contract negotiation & 3.09 & 3.00 & 2.33 & 3.44 \\
Formal commitment & 3.08 & 3.17 & 2.75 & 2.96 \\
Construction & 2.53 & 2.28 & 2.00 & 2.96 \\
Post - construction & & & & \\
\hline Average risk rating & $\mathbf{2 . 9 8}$ & $\mathbf{3 . 0 8}$ & $\mathbf{2 . 6 2}$ & $\mathbf{2 . 9 2}$ \\
\hline
\end{tabular}

\section{PROPERTY DEVELOPMENT IMPLICATIONS}

Property development is inherently risky, with a number of risks evident throughout the property development process. This sees property developers using a range of sophisticated quantitative and qualitative procedures to assess the various elements of property development risk.

Based on a survey of leading property developers in Australia, this study has identified and prioritised the key property development risks as identified by the leading property developers in Australia. The most important risk factors were environmental risk, time delay risk and land cost risk, with the pre-construction phase being seen as having the highest overall risk level in the property development process. Developers were seen to be using a wide range of risk management strategies throughout the development process, with the key strategies to mitigate property development risk being in-house management of critical processes, quality assurance procedures and contractually allocating risk to other parties.

Overall, this study has added to the critical understanding of the risk management process in property development. Increased awareness and understanding of this complex process will see a more formal and rigorous assessment of risk recognition and the risk management planning needed at all stages of property development to mitigate these risks. 


\section{REFERENCES}

Australian Property Institute (2004), Professional Practice 2004. API : Canberra.

Booth, P., Matysiak, G. and Ormerod, P. (2002), Risk Measurement and Management for Real Estate Investment Portfolios. Investment Property Forum : London.

Byrne, P. (1996), Risk, Uncertainty and Decision-making in Property Development. E \& F N Spon : London.

Cadman, D. and Topping, D. (1995), Property Development. E \& F N Spon : London.

Cameron, S. (1990), Managing interest rate risk in real estate development. Journal of Applied Corporate Finance $3: 72-79$.

Dullisear, R. (2001), Checklist helps tick off how to avoid pitfalls during development. Australian Property Journal 36 : 509-514.

Ernst \& Young (2002), Economic Impact of the Development Industry in Queensland, 2001/02. Ernst \& Young : Sydney.

Ernst \& Young (2003), Economic Impact of the Development Industry in NSW, 2001/02. Ernst \& Young : Sydney.

Markham, J. (2001), Development finance: analysing structures here and internationally. Australian Property Journal 36 : 695-703.

Miles, M., Haney, D. and Berens, G. (2000), Real Estate Development: Principles and Process. Urban Land Institute: Washington.

Pyhrr, S., Roulac, S. and Born, W. (1999), Real estate cycles and their strategic implications for investors and portfolio managers in the global economy. Journal of Real Estate Research 18 : 7-68.

Standards Australia and Standards New Zealand (1999), Australian/New Zealand Standard: Risk Management - AS/NZ 4360 : 1999.

Tan, Y.K. (2004), Is development good for LPTs? Property Australia 19(3) : 50-51.

UBS (2005), Real Estate Monthly Report: January 2005. UBS: Sydney.

Urban Development Institute of Australia (2003), The Development Industry - NSW's Engine Room. Developers Digest $3: 12-13$.

Whipple, T. (1988), Evaluating development projects. The Valuer (Oct) : 158-170. 